\title{
Monitoring canopy bird activity in disturbed landscapes with automatic recorders: A case study in the tropics
}

\author{
Ducrettet Manon ${ }^{1}$, Forget Pierre-Michel 2, Ulloa Juan Sebastian ${ }^{1,6}$, Yguel Benjamin ${ }^{3}$, \\ Gaucher Philippe ${ }^{4}$, Prince Karine ${ }^{5}$, Haupert Sylvain ${ }^{7}$, Sueur Jérôme ${ }^{1, *}$
}

1 Sorbonne Univ, Inst Systemat Evolut Biodiversite ISYEB, Museum Natl Hist Nat, CNRS,EPHE, 57 Rue Cuvier, F-75005 Paris, France.

2 Museum Natl Hist Nat, CNRS, Mecanismes Adaptatifs \& Evolut MECADEV, 1 Ave Petit Chateau, F91800 Brunoy, France.

${ }^{3}$ Sorbonne Univ, Ctr Ecol \& Sci Conservat CESCO, CNRS, Museum Natl Hist Nat, 57 Rue Cuvier, F75005 Paris, France.

4 Univ Guyane, Lab Ecol Evolut Interact Syst Amazoniens, USR 3456 CNRS, Cayenne, France.

5 UCB Lyon 1, Biometrie \& Biol Evolut LBEE, 43 Bd 11 Novembre 1918, F-69100 Villeurbanne, France.

${ }^{6}$ Inst Invest Recursos Biol Alexander von Humboldt, Av Circunvalar 16-20 Venado Oro, Bogota, DC, Colombia.

7 Sorbonne Univ, UMR 7371, UMR S 1146, Lab Imagerie Biomed,CNRS,INSERM, Paris, France.

*Corresponding author : Jérôme Sueur, email address : sueur@mnhn.fr

\begin{abstract}
:
Tropical forests are facing threats that may affect the dynamics of seed dispersers which participate in the forest regeneration. To implement appropriate conservation programs, it appears necessary to monitor seed dispersers and to estimate their response to local changes. Here, we used non-invasive ecoacoustic methods to monitor the activity of a canopy bird, the White-throated toucan, Ramphastos tucanus, a major seed disperser and flagship species of the Amazonian forest. We deployed nine acoustic recorders over 29 days along a road that connects French Guiana to Brazil. We used template matching to automatically detect the vocalizations of $R$. tucanus. This method, which can easily be repeated with limited human expertise, detected 1748 recordings with $R$. tucanus vocalizations. A GLMM analysis was applied to test for a possible effect of habitat type and human activity, while accounting for time of the day and rainfall. The number of vocalizations varied according to time of the day with peaks at dawn and dusk. The number of vocalizations did not differ significantly among sites, they were not affected by habitat type, and they were only marginally influenced by human activity. These results indicate that the vocal activity of a key conservation species can be monitored automatically in a non-invasive way. The species targeted, R. tucanus, does not seem to be significantly impacted by the road and local human activity. This might be related to the mobility of the species, which can easily cross the road, as well as low local forestry pressure.
\end{abstract}

Keywords : Biodiversity monitoring, Tropical forest, Ecoacoustics, Human activity 


\section{Introduction}

Biodiversity monitoring is a key element of conservation as it provides essential information about species occurrence, population dynamics, community composition and ecosystem structures (Foden et al., 2013). Monitoring can be done using several techniques including traditional counting (Turner, 2014), camera trapping (Steenweg et al., 2017), remote sensing (Turner et al., 2003), and environmental DNA (Thomsen and Willerslev, 2015). During the last decade, passive acoustic sensors have opened new paths for biodiversity monitoring in both underwater (Buscaino et al., 2016; Caruso et al., 2017; Parks et al., 2014; Yack et al., 2013) and terrestrial habitats (Aide et al., 2013; Buxton et al., 2018; Fristrup and Mennitt, 2012; Sugai et al., 2019). Ecoacoustics seeks to track species changes over large areas and over long time periods using standardized protocols based on unattended and non-invasive recording techniques (Sueur and Farina, 2015). The success of ecoacoustics is particularly salient for monitoring tropical forests, giving the opportunity to study animal diversity (Deichmann et al., 2018), landscape use (Burivalova et al., 2018), biological invasion (Gasc et al., 2018), mining (Duarte et al., 2015), gas exploitation (Deichmann et al., 2017), illegal hunting (Astaras et al., 2017), and logging (Sharma, 2018). 
However, ecoacoustics has not yet been employed to study the maintenance of tropical forests functions which may depend mainly on plant-animal interactions (Corlett and Primack, 2011; Redford, 1992; Wright, 2003). Animals compensate for plant immobility by transporting plant propagules, gametes and seeds, partly ensuring plant dispersion. In return, plants provide nutritional resources to animals through fruit pulp, pollen or nectar (Wunderle, 1997). The structure and resilience of tropical forests is thought to be therefore tightly linked to animal movements and feeding behavior (Holbrook and Loiselle, 2007). Population growth impacts tropical regions where 50 \% of human beings are projected to live by 2050 (Campbell, Mason; Alamgir, Mohammed; Laurance, 2017). Human activities have an obvious effect on tropical rainforests through wood exploitation and also a significant impact on animal dispersers through habitat fragmentation, illegal trade, and defaunation (Campbell, Mason; Alamgir, Mohammed; Laurance, 2017; Dirzo et al., 2014; Laurance et al., 2009; Yguel et al., 2019). There is therefore a need to better monitor the populations of seed dispersers which may play a major role in tropical rainforest dynamics, and whose presence is a valuable indicator of forest status (Boissier et al., 2020, 2014; Lewis et al., 2015). Monitoring canopy seed dispersers is a challenging task due to the difficulty of accessing to the canopy (Erwin, 2001; Kays and Allison, 2001). Ecoacoustic techniques offer new solutions to monitor wildlife in large areas providing information about species behaviour and ecology while avoiding tree climbing or the construction of canopy access infrastructures (Shonfield and Bayne, 2017). Here we took advantage of these emerging techniques to build a continuous survey of a major canopy seed disperser, the toucans (Galetti et al., 2000; Holbrook and Loiselle, 2009, 2007). 
These charismatic birds, which represent flagship species for tropical forests, are widely distributed across Central and South America. However, anthropogenic disturbances are quickly increasing in this region including expanding energy infrastructure and road networks, exacerbated by illegal activities (Barber et al., 2014; Laurance et al., 2001). Toucans are categorized as vulnerable due to hunting, illegal trade and habitat modification (IUCN, 2016). Toucans are generalist frugivores that roost in tree cavities (Galetti et al., 2000; Short and Horne, 2001) and disperse seeds by moving in various types of forest habitats depending on fruit resources availability (Holbrook, 2011; Short and Horne, 2001). Despite these key roles as flagship species and seed dispersers, the population dynamics of toucans are poorly known, probably due to the difficulty to monitor them on the long term.

French Guiana, which contains important continuous tracts of neotropical forest, is currently facing a rise in human activity including hunting, as well as urban area and road expansion (de Thoisy et al., 2005; Richard-Hansen et al., 2019). Roads and human disturbances such as illegal mining, logging and hunting are intertwined as roads facilitate access to the forest (Campbell, Mason; Alamgir, Mohammed; Laurance, 2017; Coffin, 2007; de Thoisy et al., 2005; Robinson and Redford, 1994). These human activities are thought to increase forest fragmentation and simplify the access by hunters to seed disperser populations.

We aimed at testing the effect of habitat type and human activity on the vocal activity of the White-throated toucan, Ramphastos tucanus, as well as considering the time of the day and rainfall which are known to mediate tropical bird activity. In particular, we hypothesized that logging would decrease toucan vocal activity. To test this prediction, we deployed an acoustic monitoring system in the southeastern part of French Guiana where the road network has been recently expanded to directly connect French Guiana and Brazil. 


\section{Material and methods}

\subsection{Study site}

The study was conducted in a lowland forest of the Guiana Shield, a key area for neotropical forest conservation due to a high level of diversity and endemism (de Thoisy et al., 2010, 2005). The climate is humid equatorial with an alternation of a rainy season with two dry seasons: the first dry season from February to March, and the second dry season from September to October. The study area has a mean annual precipitation rate of 3,364 $\mathrm{mm}$ and a mean annual temperature of $27^{\circ} \mathrm{C}$. The site is an old-growth mature forest along the Route Nationale 2 (RN2) that connects the urban agglomeration of the Ile-de-Cayenne or Cayenne Peninsula (109,358 inhabitants in 2014) to the small city of Saint-Georges-de-l'Oyapock (4,020 inhabitants in 2015), and to the middle size Brazilian city of Oiapoque (25,514 inhabitants in 2017) through a bridge over the river Oyapock (Fig. 1). To favor road crossing by wildlife and to maintain connectivity, 13 forested corridors acting as overpasses for canopy animals have been established over the road by local authorities. These corridors mainly consist of keeping the canopy intact above the road.

\subsection{Study species}


Most bird species, in particular tropical species, communicate with sound in different contexts such as territory defense, courtship display, group cohesion or parent-offspring interactions (Mathevon et al., 2008). Ramphastos tucanus produces sound when moving in groups maintaining contact between individuals. The vocalizations are loud, highly repeated, and stereotyped, all conditions necessary for developing an automatic recognition by template matching (Bardeli et al., 2010; Ulloa et al., 2016). Preliminary analyses revealed that the vocalizations of $R$. tucanus are made of two notes, a first note ranging from $1.4 \mathrm{kHz}$ to 1.8 $\mathrm{kHz}$ and a second longer note ranging from $1.3 \mathrm{kHz}$ to $1.5 \mathrm{kHz}$, leading to a call type "keeowyelp-yelp” (Fig. 2).

2.3. Acoustic survey 
We conducted an acoustic survey to estimate the absence/presence of $R$. tucanus vocalizations near 9 of the 13 corridors (hereafter named A-I) along the Route Nationale 2 (RN2), so that the forest was regularly sampled along $43 \mathrm{~km}$ of the road with independent sampling units (Fig. 1). For each sampled forest corridor, we installed one automatic recording unit, Song Meter 4 (Wildlife Acoustics, USA), on a tree trunk near a Virola tree (V. kwatae, V. michelii, and $V$. surinamensis, Myristicaceae), known to be visited by $R$. tucanus. We oriented the integrated microphones to minimize the noise from the road. We placed each recorder on the tree trunk at $2 \mathrm{~m}$ above the ground. The distance to the road was between 200 and 300 meters avoiding a potential edge effect of the road. We set up the recorders to record 1 min every 10 $\min$ ( 1 min of recording, 9 min of pause) for 24 hours/days with a sampling frequency of 44.1 $\mathrm{kHz}$, a digitization depth of 16 bit and a gain of $+16 \mathrm{~dB}$. We used internal microphones that have a flat frequency response $\pm 6 \mathrm{~dB}$ between 0.06 and $20 \mathrm{kHz}$ and a full flat frequency response between 1.4 and $1.8 \mathrm{kHz}$ corresponding to the frequency range of $R$. tucanus. The sampling period covered one month from 2017-11-26 to 2017-12-24 (29 days), at the beginning of the rainy season. This sampling generated an audio dataset of 37,584 files. We could not estimate the space covered by each recorder due to the intricate structure of the forest and a high diversity of sound sources. However, a sound propagation law model for similar habitat estimated a recording radius of $120 \mathrm{~m}$ for a sound source of $80 \mathrm{~dB}$ SPL (unpublished results). This corroborates previous experiments indicating a radius of 100 m (Rodriguez et al., 2014; Ulloa et al., 2016). We therefore estimated that each recorder monitored an area of ca. 3 ha, i.e. a circle with a radius of approximately $98 \mathrm{~m}$.

\subsection{Automatic acoustic identification}




\subsubsection{Datasets}

In order to build, tune and evaluate the detection system we selected from the full dataset the recordings from the day period, from 5 am to 8 pm, and randomly sampled 900 files. This sample was manually annotated with presence/absence of toucan vocalizations and included different weather conditions. These files were split into a training set and a validation set. The training set included 451 files of which 37 had presence of toucan vocalizations, and the validation set included 449 files of which 37 had presence of toucan vocalizations. All acoustic analyses were performed with seewave (Sueur et al., 2008) and monitoR (Katz et al., 2016a, 2016b) R packages. Classification was assessed by measuring the Area Under the Curve (AUC) of the Receiver Operating Characteristic (ROC) with the R package $p R O C$ (Robin et al., 2011). 


\subsubsection{Template selection}

The presence of toucans was detected through a template matching process. Templates should be representative of the sound of interest, here toucan vocalizations, and of the acoustic environment, so it is recommended to select templates from local recordings. This local selection helps to maximize positive identification and minimize false identification due to background noise and/or the vocalizations of other species occupying the same bandwidth as the sound of interest (Katz et al., 2016a). Here, we selected the best toucan vocalizations ( $\mathrm{n}=$ 33) to extract relative invariant temporal and spectral features of the call (Fig. 2). We applied a finite impulse response (FIR) band-pass frequency filter between $1 \mathrm{kHz}$ and $2 \mathrm{kHz}$ so that we focused on the fundamental frequency that was the most conserved element (Priyadarshani et al., 2018). We then tested the 33 templates on the training dataset following the same steps as described in section 2.4.4. The two templates with better classification performance combining the first ("keeow”) and the second ("yelp”) syllables returned an AUC of 0.9184 and were selected for further analysis (Fig. A1). 


\subsubsection{Spectrogram cross-correlation}

The automatic detection consisted of a comparison of the spectral and temporal features of the template with the recording at different time lags through a non-overlapping moving window. The template recording comparison was achieved with a cross-correlation at each time lag $T$. The process was based on a short-term Fourier transform (STFT) between the template and the recording. A previous analysis showed that a Fourier transform (FT) of 512 samples tapered with a Hanning window returned the most appropriate results (Ulloa et al., 2016). The index of similarity $R_{x y}$, or correlation coefficient was obtained with the following equation for two time-series $x(\mathrm{t})$ and $y(\mathrm{t})$ of 1 min recording (Sueur, 2018):

$$
R_{x y}[T]=\frac{\sum_{t=1}^{N-T} x[t] y[t+T]}{\left(\sum_{t=1}^{N-T} x^{2}[t] \sum_{t=1}^{N-T} y^{2}[t]\right)^{\frac{1}{2}}} \text { where } R_{x y}[T] \text { is a series of correlation coefficients along time }
$$

for each value of $T$.

The higher the score, the higher the similarity between template and audio, and hence a higher probability that a toucan vocalization is occurring in the recording. The score is then translated into binary information in reference to a threshold. Values above (respectively below) the threshold indicate a positive (respectively negative) detection (Katz et al., 2016b). As we were estimating the absence/presence of $R$. tucanus vocalizations in each recording, we did not search for all vocalizations occurring in each recording but we only considered the most salient one, that is the vocalization that returned the highest correlation with the templates. 


\subsubsection{Evaluation of the automatic detection system}

We tuned the automatic detection system on the training dataset by matching the ground truth dataset (manual classification) with the predictions (automatic classification). We obtained a confusion matrix with four categories of detections: true positive (TP), false negative (FN), false positive (FP) and true negative (TN). The metrics used were the true positive rate (TPR $=\mathrm{TP} /(\mathrm{TP}+\mathrm{FN}))$ and the false positive rate $(\mathrm{FPR}=\mathrm{FP} /(\mathrm{FP}+\mathrm{TN}))$. The automatic detection system and the resulting binary classification involve a decision on a reference threshold on which the relative frequencies of the different categories depend so that the threshold adjusts the global error of the automatic system. Setting a low threshold increases the number of TP and FP detections and decreases the number of FN. Here, we chose a threshold of 0.54 to get the best compromise between TPR and FPR (Priyadarshani et al., 2018). This high value limits FP detections due to the occurrence of a complex interfering background made by vocalizations of other species. Most FP detections were due to the Great tinamou (Tinamus major), and the Screaming Piha (Lipaugus vociferans). FN detections were in most cases soft vocalizations of distant $R$. tucanus or vocalizations of close individuals but blurred by noise resulting from rainfall. 
The tuned automatic system was validated on the validation dataset with the chosen threshold of 0.54 . The automatic system correctly classified 15 toucan vocalizations (TP), missed 18 (FN), misclassified 22 as toucan vocalizations (FP) and correctly classified 386 recordings as vocalizations produced by other sound sources (TN). The automatic system therefore detected $45 \%$ of the labeled vocalizations, with an FPR of $5 \%$. This implied a rather low true detection rate but minimized misclassification and ensured to detect only close by vocalizations.

\subsection{Environmental data}

We used a GIS analysis with QGIS desktop 2.18.17 and GRASS 7.4.0 to assess abiotic and biotic factors in the context of local human activity (Morrison et al., 2006). We delimited a buffer zone of 64.5 ha similarly around each recorder. This larger zone corresponded to the median home range area of $R$. tucanus (Holbrook, 2011). We estimated three environmental variables inside the 64.5 ha area: (1) habitat type, (2) human activity, and (3) rainfall. 
Habitat type was defined according to the geomorphodiversity and forest composition that appear as the most important factors in shaping the forest of French Guiana (Guitet et al., 2015). There were three types of forests: plateau forests, transitional forests along creeks and small ravines, and riparian forests. Plateau forests were well drained forests mainly composed of Burseraceae such as Protium spp, Fabaceae, Lecythidaceae and Mimosaceae. Transitional forests were relatively humid areas where vegetation composition was similar to both riparian forests and plateau forests. Riparian forests were found at a low elevation with waterlogged soil with, palm trees (Euterpe oleracea), Virola surinamensis (Myristicaceae) and Eperua falcata (Fabaceae). The three types of forest provide important resources to toucans as they all include trees with fruits. More specifically Virola spp provide early fresh fruits with a fructification period from September to March (Mendoza et al., 2018; Ratiarison and Forget, 2013). Furthermore, palm trees such as Euterpe spp. and Protium spp. were also a key alternative food resource during the dry season when fruits are scarce (Thiollay, 2005). We encoded the forest habitat types by creating an empirical classification of two habitat types (1 and 2) based on the percentage of forest types (Table A1). The differences in forest types were numerically small (about 5\%) but still meaningful as such forest types indicate different water and food resources that are particularly important for toucans during the dry season.

Human activity, either positive or negative, came from the data provided by government offices (Office National des Forêts; Direction de l'Environnement, de l'Aménagement et du Logement). Human activity variable integrated protected areas (i.e. with a low hunting pressure), agriculture and logging intensity encoded with different exploitation rates (medium, high), so that the variable included four levels (protected - corridors E,F; agriculture corridor A; medium logging - corridors B, G, H, I; high logging -corridors C,D). 
Rainfall data were obtained from the meteorological station of Saint-Georges-del'Oyapock $\left(3.88^{\circ} \mathrm{N}, 51.80^{\circ} \mathrm{W}, 6 \mathrm{~m}\right.$ a.s.l.). The data were downloaded as rainfall level in $\mathrm{mm}$ per a six min period and then summed up for each hour.

\subsection{Statistical analysis}

To investigate the effects of habitat type and human activity considering rainfall and day time on toucan vocal activity, we used a Generalized Linear Mixed Model (GLMM) assuming a Poisson error distribution and a log-link function to model the number of detections (Bolker et al., 2009). The response variable was the number of recordings in which vocalizations were detected per hour. Habitat type and human activity were categorical variables that were included as fixed effects, as well as rainfall and hour that may affect acoustic activity. To account for data non-independence according to both space and time, we included sites and day as crossed random effects. The full model was fitted using the function $\operatorname{glmm} T M B()$ from the R package $\operatorname{glmm} T M B$ (Brooks et al., 2017a). 
Given the nature of the response variable (count), we tested for potential overdispersion in the model residuals (Zuur et al., 2009). The dispersion statistic of the Poisson GLMM fitted to the data showed that the model was overdispersed. Hence, we fitted the next model in complexity with a negative binomial GLMM (Lindén and Mäntyniemi, 2011). Since we did not have information about the relation between the variance and the mean, we fitted a first full model with a negative binomial of type I (that allows the variance to increase linearly with the mean), and another full model with a negative binomial error distribution of type II (that models a quadratic relation between the variance and the mean) (Brooks et al., 2017b). The model with a negative binomial error distribution of type I was found the most parsimonious with the lowest Akaike’s criterion (AIC) value (i.e. dAIC<2; (Burnham et al., 2002)).

Before performing our model, we examined the correlations among explanatory variables using the variance inflation factor (VIF), with the function vif() from the R package car (Fox and Weisberg, 2011) applied to the standard linear model without random effects. All variables had a VIF $<3$ indicating no problem of multicollinearity (Zuur et al., 2009). We also inspected spatial correlograms based on the model residuals (Zuur et al., 2009) in order to detect any sign of spatial autocorrelation, which we did not find. 
We checked that our final model provided a good fit after checking the assumptions on residuals independence, homogeneity and normality using a quantile-quantile plot, and the simulate residuals with the R package DHARMa (Hartig, 2018; Steel et al., 2013). The response variable included many zeros, due to failure of detection, absence of $R$. tucanus, or a decrease in vocal activity. A high number of zeros can lead to the zero-inflation issue and bias the parameters estimation (Bolker et al., 2017). Therefore, we verified that the fitted model was not zero-inflated with the function testZeroInflation() from the R package DHARMa.

We extracted the estimates and interpreted the models with the Incidence Rate Ratios (IRR) which clearly illustrate the links between model prediction and explanatory variables (Hilbe, 2011). For the fixed effects, the predictor levels taken in reference were the habitat type “1”, the human activity "agricultural area”, and the hour "5 am”.

The model did not include a temporal link between rain events and vocal activity of $R$. tucanus. As such, to further evaluate a potential relationship between vocal activity and rainfall over time (i.e. throughout the survey period) we ran a Dynamic Time Warping (DTW) analysis. This method minimizes the Euclidean distance between two paths or time series through local compression or stretching (Giorgino, 2009). Since we wanted to evaluate the alignment between the rainfall that is a quantity in millimeters and the number of vocalizations detected, quantitative variables were Z-transformed beforehand.

All the analyses were performed with R software version 3.4.4 (R Core Team, 2018).

\section{Results}


The automatic detection system based on the cross-correlation with two templates detected, between 5:00 am and 8:00 pm a total of 1,748 files with at least one vocalization over the 22,490 audio files.

3.1 Vocal activity according to time of the day

According to the model (Tab. 1), there was a significant hour effect in the number of detections from 5:00 am to 10:00 am and from 4:00 pm to 7:00 pm $(\mathrm{p}<0.05)$ with a marginal effect $(p=0.059)$ at 3:00 pm. There was therefore a diurnal activity pattern with a dawn chorus, afternoon rest, and a dusk chorus (Figs. 3-4).

3.2 Vocal activity according to habitat and human activity

Habitat type did not show any significant effect on the number of detections. The human activity had a significant effect only in the area of high logging exploitation with the number of detections 1.57 times higher than the number of detections in the agricultural sites (Tab. 1).

3.3 Vocal activity according to rainfall 
According to the mixed model developed (GLMM), rainfall quantity did not significantly influence the number of detections (Tab. 1). However, when comparing the daily rainfall event time series with the number of detections time series across all sites - at the forest scale - using the DTW method (Fig. 5), we found that the vocal activity is on average higher and more variable before the $11^{\text {th }}$ of December related to a low rainfall. The DTW alignment between the two-time series showed that there was a temporal link for four days between the number of detections and the rain events, so that the number of detections increased before heavy rain events (Fig. 5).

\section{Discussion}

Ecoacoustics was used to evaluate how time of the day, rainfall, habitat and human activity may influence the acoustic activity of the White-throated toucan (R. tucanus), a canopy flagship species for neotropical forest conservation. 
The passive acoustic monitoring (PAM) system was based on an array of nine recorders recording continuously over 29 days, returning a total of 391 hours of data, equivalent to nearly 48 days of human work. The audio files were screened out using an automatic system already tested (Ulloa et al., 2016) and was based on a limited expertise as it was only necessary to identify few toucan vocalizations, a skill that can be acquired very quickly by exploring the forest or, even more simply, by visiting online sound libraries. The system can be therefore considered as simple, efficient and accessible to non-experts. Several studies have shown that similar PAM systems can be as informative as point count sampling technique traditionally used in conservation programs (Haselmayer and Quinn, 2012; Shonfield and Bayne, 2017; Stevens et al., 2019). 
Animal vocal activity is known to change during the night/day cycle corresponding with environmental factors and behaviors such as courtship or territorial defense (Boscolo et al., 2006; Digby et al., 2014; Goymann et al., 2012). These cyclic variations, or phenological patterns, are a key element of animal ecology (Forrest and Miller-Rushing, 2010). Particularly, birds have a developed circadian system in link with biological function as singing (Cassone and Westneat, 2012). Here, the vocalizations detected over all sites clearly showed that the vocal activity of $R$. tucanus was not even along the day but irregular with major peaks of activity at 6:00 am and 06:00 pm around sunrise and sunset. This behavioral phenology fits with the usual, but not universal, chorus behavior of birds at dawn and at dusk for which a total of twelve ecological and evolutionary hypotheses have been put forward (Burt and Vehrencamp, 2005). Knowing this time pattern is crucial in terms of sampling efficiency in monitoring programs. Further conservation studies dealing with population structure and dynamics should now focus on dawn and dusk time to monitor $R$. tucanus in order to optimize detections and to save by a factor of six (four hours of monitoring instead of 24 hours) battery and data storage, two important limiting factors of sampling based on digital techniques. 
Weather parameters such as temperature, wind speed and barometric pressure play an important role in animal acoustic phenology. Rain may have a particularly direct detrimental effect on the bird vocal activity through masking due to the sound produced by raindrops striking the vegetation (Lengagne and Slater, 2002). Here, we could observe that rainfall, a major element of tropical climate, may have a positive lagged effect on the vocal activity of $R$. tucanus that appeared to increase before rain. This unexplained behavior was actually already reported by local people and field observations (Short and Horne, 2001). The daily pattern and the rainfall effect should now be tested over a longer period including dry and rainy seasons in order to have more information about seasonality. This should also open the possibility to document the seasonal migrations of $R$. tucanus over the year from the inner to the coastal forest, and possibly over several years in relation to climate change and so to possible seasonal shifts. 
In addition to temporal variation, we looked for spatial patterns related to habitat types and human activity. There was no effect of the habitat type nor of human activity on the calling activity of $R$. tucanus. This lack of significant difference of habitat types was probably due to the fact that the nine sites were relatively homogeneous in terms of habitat characteristics with no obvious differences in relative proportion of plateau, transition, and riparian forests. All habitat types probably provide the food resources necessary for $R$. tucanus in particular with the occurrence of Virola trees in the plateau forest, and, alternatively, of Euterpe palm trees in the riparian forest. In addition, toucans are quite mobile so the road might not represent an obstacle to their movement across the forest. There was no significant effect of human activity on toucan vocal activity suggesting that the toucans were not impacted by the local tree exploitation, either along the road or further inside. Local forestry does not seem to affect toucans contrary to what was observed for other species found in sites where logging was shown to significantly decrease the number of singing individuals and to shift the vocal activity because of chainsaw and road traffic noise (Slabbekoorn and Ripmeester, 2008). Unexpectedly, we found a significant higher number of vocalizations in the sites which were the most logged. However, logging was sparse with only a few trees logged per hectare following local regulation so that canopy opening was not different compared to natural forest dynamics with regular treefall regime (i.e. one gap per ha per year) (van der Meer \& Bonger, 1996). Therefore logging did not affect canopy opening so that different sound propagation conditions that might have an effect on detection were unlikely. This result could be explained by a competition between $R$. tucanus and the Black Spider monkey, Ateles paniscus. The Black Spider monkey is also an important fruit consumer and seed disperser of Virola spp. (Forget and Sabatier, 1997; Ratiarison and Forget, 2013). In the 
context of a logged forest, toucans have an easier access to the canopy than monkeys, so a decrease in A. paniscus populations may benefit $R$. tucanus (Felton et al., 2010; Holbrook, 2011).

Toucans are highly visible species often used as icons for tourism and commercial use in all sorts of representations (Correia et al., 2016) but they are also highly hunted (Thiollay, 2005). Being both icon and game species, R. tucanus and its sister species of the Ramphastidae family, have a dual importance in terms of culture and conservation. Thus, their monitoring is crucial. (Astaras et al., 2017; Boissier et al., 2020; Hill et al., 2018) 
Ecoacoustic monitoring based on only nine recorders settled at human height and combining here vocal activity detection and habitat description revealed key cues for canopy management since population viability and habitat are closely linked (Morrison et al., 2006). Toucans are essentially sedentary but movements towards the coastal area have been reported. Providing information using ecoacoustics about the occurrence of $R$. tucanus was the first necessary step towards a potential monitoring and conservation program over a long term. However, the habitats offered by the coastal area are facing increasing anthropogenic pressures due to human population growth. The resident zone we monitored might then be the only refuge for toucans and potentially other seed dispersers underlying the importance of their monitoring and protection. Over the next years, the bridge connecting French Guiana to Brazil is expected to increase human activity along the road and become a more important driver of the defaunation process. . This could lead to defaunation resulting from an increase in bushmeat consumption or habitat destruction with urban and agriculture area expansion (Young et al., 2016). Ecoacoustic methods can gather data not only on a target species but also on all other species sharing the same habitat. The recordings collected here could then be used to investigate similar ecological questions on other canopy species such as other birds or primates. 


\section{References}

Aide, T.M., Corrada-Bravo, C., Campos-Cerqueira, M., Milan, C., Vega, G., Alvarez, R., 2013. Real-time bioacoustics monitoring and automated species identification. PeerJ 1, e103. https://doi.org/10.7717/peerj.103

Astaras, C., Linder, J.M., Wrege, P., Orume, R.D., Macdonald, D.W., 2017. Passive acoustic monitoring as a law enforcement tool for Afrotropical rainforests. Front. Ecol. Environ. 15, 233-234. https://doi.org/10.1002/fee.1495

Barber, C.P., Cochrane, M.A., Souza, C.M., Laurance, W.F., 2014. Roads, deforestation, and the mitigating effect of protected areas in the Amazon. Biol. Conserv. 177, 203-209. https://doi.org/10.1016/J.BIOCON.2014.07.004

Bardeli, R., Wolff, D., Kurth, F., Koch, M., Tauchert, K.-H., Frommolt, K.-H., 2010. Detecting bird sounds in a complex acoustic environment and application to bioacoustic monitoring. Pattern Recognit. Lett. 31, 1524-1534. https://doi.org/10.1016/j.patrec.2009.09.014

Boissier, O., Bouiges, A., Mendoza, I., Feer, F., Forget, P.-M., 2014. Rapid Assessment of Seed Removal and Frugivore Activity as a Tool for Monitoring the Health Status of Tropical Forests. Biotropica 46, 633-641. https://doi.org/10.1111/btp.12134

Boissier, O., Feer, F., Henry, P.-Y., Forget, P.-M., 2020. Modifications of the rainforest frugivore community are associated with reduced seed removal at the community level. Ecol. Appl. n/a. https://doi.org/10.1002/eap.2086

Bolker, B.M., Brooks, M.E., Clark, C.J., Geange, S.W., Poulsen, J.R., Stevens, M.H.H., 
White, J.-S.S., 2009. Generalized linear mixed models: a practical guide for ecology and evolution. Trends Ecol. Evol. 24, 127-135. https://doi.org/10.1016/j.tree.2008.10.008

Bolker, B.M., Nielsen, A., Van Benthem, K.J., Skaug, H.J., Berg, C.W., Brooks, M.E., Magnusson, A., Mächler, M., Kristensen, K., 2017. glmmTMB balances speed and flexibility among packages for zero-inflated generalized linear mixed modeling. https://doi.org/10.5167/uzh-148918

Boscolo, D., Metzger, J.P., Vielliard, J.M.E., 2006. Efficiency of playback for assessing the occurrence of five bird species in Brazilian Atlantic Forest fragments. An. Acad. Bras. Cienc. 78, 629-644. https://doi.org/10.1590/S0001-37652006000400003

Brooks, M.E., Kristensen, K., van Benthem, K.J., Magnusson, A., Berg, C.W., Nielsen, A., Skaug, H.J., Maechler, M., Bolker, B.M., 2017a. \{glmmTMB\} Balances Speed and Flexibility Among Packages for Zero-inflated Generalized Linear Mixed Modeling. R J. 9, 378-400.

Brooks, M.E., Kristensen, K., van Benthem, K.J., Magnusson, A., Berg, C.W., Nielsen, A., Skaug, H.J., Maechler, M., Bolker, B.M., 2017b. Modeling Zero-Inflated Count Data With glmmTMB. https://doi.org/10.1101/132753

Burivalova, Z., Towsey, M., Boucher, T., Truskinger, A., Apelis, C., Roe, P., Game, E.T., 2018. Using soundscapes to detect variable degrees of human influence on tropical forests in Papua New Guinea: Tropical-Forest Soundscapes. Conserv. Biol. 32, 205-215. https://doi.org/10.1111/cobi.12968

Burnham, K.P., Anderson, D.R., Burnham, K.P.C.N.-Q.. . B. 2002, 2002. Model selection and 
multimodel inference: a practical information-theoretic approach, 2nd ed. ed. Springer, New York.

Burt, J.M., Vehrencamp, S.L., 2005. Dawn chorus as an interactive communication network, in: McGregor, P.K. (Ed.), Animal Communication Networks. Cambridge University Press, Cambridge, pp. 320-343.

Buscaino, G., Ceraulo, M., Pieretti, N., Corrias, V., Farina, A., Filiciotto, F., Maccarrone, V., Grammauta, R., Caruso, F., Giuseppe, A., Mazzola, S., 2016. Temporal patterns in the soundscape of the shallow waters of a Mediterranean marine protected area. Sci. Rep. 6, 34230.

Buxton, R.T., Agnihotri, S., Robin, V. V, Goel, A., Balakrishnan, R., 2018. Acoustic indices as rapid indicators of avian diversity in different land-use types in an Indian biodiversity hotspot. J. Ecoacoustics 2, GWPZVD. https://doi.org/10.22261/JEA.GWPZVD

Campbell, Mason; Alamgir, Mohammed; Laurance, W., 2017. Roads to ruin. Australas. Sci.

Caruso, F., Alonge, G., Bellia, G., De Domenico, E., Grammauta, R., Larosa, G., Mazzola, S., Riccobene, G., Pavan, G., Papale, E., Pellegrino, C., Pulvirenti, S., Sciacca, V., Simeone, F., Speziale, F., Viola, S., Buscaino, G., 2017. Long-Term Monitoring of Dolphin Biosonar Activity in Deep Pelagic Waters of the Mediterranean Sea. Sci. Rep. 7, 4321. https://doi.org/10.1038/s41598-017-04608-6

Cassone, V.M., Westneat, D.F., 2012. The bird of time: cognition and the avian biological clock. Front. Mol. Neurosci. 5, 32. https://doi.org/10.3389/fnmol.2012.00032

Coffin, A.W., 2007. From roadkill to road ecology: A review of the ecological effects of 
roads. J. Transp. Geogr. 15, 396-406. https://doi.org/10.1016/j.jtrangeo.2006.11.006

Corlett, R.T., Primack, R.B., 2011. Tropical Rain Forests: An Ecological and Biogeographical Comparison: Second edition, Tropical Rain Forests: An Ecological and Biogeographical Comparison: Second edition. https://doi.org/10.1002/9781444392296

Correia, R.A., Jepson, P.R., Malhado, A.C.M., Ladle, R.J., 2016. Familiarity breeds content: assessing bird species popularity with culturomics. PeerJ. https://doi.org/10.7717/peerj.1728

de Thoisy, B., Renoux, F., Julliot, C., 2005. Hunting in northern French Guiana and its impact on primate communities. Oryx 39. https://doi.org/10.1017/S0030605305000384

de Thoisy, B., Richard-Hansen, C., Goguillon, B., Joubert, P., Obstancias, J., Winterton, P., Brosse, S., 2010. Rapid evaluation of threats to biodiversity: human footprint score and large vertebrate species responses in French Guiana. Biodivers. Conserv. 19, 1567-1584. https://doi.org/10.1007/s10531-010-9787-z

Deichmann, J.L., Acevedo-Charry, O., Barclay, L., Burivalova, Z., Campos-Cerqueira, M., d’Horta, F., Game, E.T., Gottesman, B.L., Hart, P.J., Kalan, A.K., Linke, S., Nascimento, L. Do, Pijanowski, B., Staaterman, E., Mitchell Aide, T., 2018. It’s time to listen: there is much to be learned from the sounds of tropical ecosystems. Biotropica 50, 713-718. https://doi.org/10.1111/btp.12593

Deichmann, J.L., Hernández-Serna, A., Delgado C., J.A., Campos-Cerqueira, M., Aide, T.M., 2017. Soundscape analysis and acoustic monitoring document impacts of natural gas 
exploration on biodiversity in a tropical forest. Ecol. Indic. 74, 39-48.

https://doi.org/10.1016/j.ecolind.2016.11.002

Digby, A., Towsey, M., Bell, B.D., Teal, P.D., 2014. Temporal and environmental influences on the vocal behaviour of a nocturnal bird. J. Avian Biol. 45, 591-599. https://doi.org/10.1111/jav.00411

Dirzo, R., Young, H.S., Galetti, M., Ceballos, G., Isaac, N.J.B., Collen, B., 2014. Defaunation in the Anthropocene. Science (80-. ). 345, 401-406. https://doi.org/10.1126/science.1251817

Duarte, M.H.L., Sousa-Lima, R.S., Young, R.J., Farina, A., Vasconcelos, M., Rodrigues, M., Pieretti, N., 2015. The impact of noise from open-cast mining on Atlantic forest biophony. Biol. Conserv. 191, 623-631. https://doi.org/10.1016/j.biocon.2015.08.006

Erwin, T.., 2001. FOREST CANOPIES, ANIMAL DIVERSITY. Encycl. Biodivers. 3, 1925. https://doi.org/10.1016/B0-12-226865-2/00125-5

Felton, A.M., Felton, A., Foley, W.J., Lindenmayer, D.B., 2010. The role of timber tree species in the nutritional ecology of spider monkeys in a certified logging concession, Bolivia. For. Ecol. Manage. 259, 1642-1649. https://doi.org/10.1016/j.foreco.2010.01.042

Foden, W.B., Mace, G.M., Butchart, S.H.M., 2013. Indicators of Climate Change Impacts on Biodiversity, in: Collen, B., Pettorelli, N., Baillie, J.E.M., Durant, S.M. (Eds.), Biodiversity Monitoring and Conservation. Wiley-Blackwell, Oxford, UK, pp. 120-137. Forget, P.-M., Sabatier, D., 1997. Dynamics of the seedling shadow of a frugivore-dispersed 
tree species in French Guiana. J. Trop. Ecol. 13, 767-773.

https://doi.org/10.1017/S0266467400010920

Forrest, J., Miller-Rushing, A.J., 2010. Toward a synthetic understanding of the role of phenology in ecology and evolution. Philos. Trans. R. Soc. B Biol. Sci. https://doi.org/10.1098/rstb.2010.0145

Fox, J., Weisberg, S., 2011. An R Companion to Applied Regression. SAGE Publications.

Fristrup, K.M., Mennitt, D., 2012. Bioacoustical monitoring in terrestrial environments. Acoust. Today 8, 16-24.

Galetti, M., Laps, R., Pizo, M.A., 2000. Frugivory by Toucans (Ramphastidae) at Two Altitudes in the Atlantic Forest of Brazil1. Biotropica 32, 842-850. https://doi.org/10.1111/j.1744-7429.2000.tb00622.x

Gasc, A., Anso, J., Sueur, J., Jourdan, H., Desutter-Grandcolas, L., 2018. Cricket calling communities as an indicator of the invasive ant Wasmannia auropunctata in an insular biodiversity hotspot. Biol. Invasions 20, 1099-1111. https://doi.org/10.1007/s10530-017$1612-0$

Giorgino, T., 2009. Computing and Visualizing Dynamic Time Warping Alignments in $R$ : The dtw Package. J. Stat. Softw. 31. https://doi.org/10.18637/jss.v031.i07

Goymann, W., Helm, B., Jensen, W., Schwabl, I., Moore, I.T., 2012. A tropical bird can use the equatorial change in sunrise and sunset times to synchronize its circannual clock. Proc. R. Soc. B Biol. Sci. 279, 3527-3534. https://doi.org/10.1098/rspb.2012.0743

Guitet, S., Pélissier, R., Brunaux, O., Jaouen, G., Sabatier, D., 2015. Geomorphological 
landscape features explain floristic patterns in French Guiana rainforest. Biodivers. Conserv. 24, 1215-1237. https://doi.org/10.1007/s10531-014-0854-8

Hartig, F., 2018. DHARMa: Residual Diagnostics for Hierarchical (Multi-Level / Mixed) Regression Models. R package version 0.2.0. https://CRAN.R-project.org/package=DHARMa.

Haselmayer, J., Quinn, J.S., 2012. A Comparison of Point Counts and Sound Recording as Bird Survey Methods in Amazonian Southeast Peru. Condor. https://doi.org/10.2307/1370317

Hilbe, J.M., 2011. Negative Binomial Regression, 2nd ed. Cambridge University Press, Cambridge. https://doi.org/DOI: 10.1017/CBO9780511973420

Hill, A.P., Prince, P., Piña Covarrubias, E., Doncaster, C.P., Snaddon, J.L., Rogers, A., 2018. AudioMoth: Evaluation of a smart open acoustic device for monitoring biodiversity and the environment. Methods Ecol. Evol. https://doi.org/10.1111/2041-210X.12955

Holbrook, K.M., 2011. Home Range and Movement Patterns of Toucans: Implications for Seed Dispersal: Toucan Movement Patterns. Biotropica 43, 357-364. https://doi.org/10.1111/j.1744-7429.2010.00710.x

Holbrook, K.M., Loiselle, B.A., 2009. Dispersal in a Neotropical tree, Virola flexuosa (Myristicaceae): Does hunting of large vertebrates limit seed removal? Ecology 90, 1449-1455. https://doi.org/10.1890/08-1332.1

Holbrook, K.M., Loiselle, B.A., 2007. Using toucan-generated dispersal models to estimate seed dispersal in Amazonian Ecuador., in: Dennis, A.J., Schupp, E.W., Green, R.J., 
Westcott, D.A. (Eds.), Seed Dispersal: Theory and Its Application in a Changing World. CABI, Wallingford, pp. 300-321.

IUCN, 2016. Ramphastos tucanus: BirdLife International: The IUCN Red List of Threatened Species 2016: e.T22682153A92932045. International Union for Conservation of Nature.

Katz, J., Hafner, S.D., Donovan, T., 2016a. Assessment of Error Rates in Acoustic Monitoring with the R package monitoR. Bioacoustics 25, 177-196. https://doi.org/10.1080/09524622.2015.1133320

Katz, J., Hafner, S.D., Donovan, T., 2016b. Tools for automated acoustic monitoring within the R package monitoR. Bioacoustics 25, 197-210. https://doi.org/10.1080/09524622.2016.1138415

Kays, R., Allison, A., 2001. Arboreal tropical forest vertebrates: current knowledge and research trends, in: Linsenmair, K.E., Davis, A.J., Fiala, B., Speight, M.R. (Eds.), Tropical Forest Canopies: Ecology and Management: Proceedings of ESF Conference, Oxford University, 12--16 December 1998. Springer Netherlands, Dordrecht, pp. 109120. https://doi.org/10.1007/978-94-017-3606-0_9

Laurance, W.F., Cochrane, M.A., Bergen, S., Fearnside, P.M., Delamônica, P., Barber, C., D\&\#039;Angelo, S., Fernandes, T., 2001. The Future of the Brazilian Amazon. Science (80-. ). 291, 438. https://doi.org/10.1126/science.291.5503.438

Laurance, W.F., Goosem, M., Laurance, S.G.W., 2009. Impacts of roads and linear clearings on tropical forests. Trends Ecol. Evol. 24, 659-669. https://doi.org/10.1016/j.tree.2009.06.009 
Lengagne, T., Slater, P.J.B., 2002. The effects of rain on acoustic communication: tawny owls have good reason for calling less in wet weather. Proc. R. Soc. B Biol. Sci. 269, 21212125. https://doi.org/10.1098/rspb.2002.2115

Lewis, S.L., Edwards, D.P., Galbraith, D., 2015. Increasing human dominance of tropical forests. Science (80-. ). https://doi.org/10.1126/science.aaa9932

Lindén, A., Mäntyniemi, S., 2011. Using the negative binomial distribution to model overdispersion in ecological count data. Ecology 92, 1414-1421. https://doi.org/10.1890/10-1831.1

Mathevon, N., Aubin, T., Vielliard, J., da Silva, M.-L., Sebe, F., Boscolo, D., 2008. Singing in the Rain Forest: How a Tropical Bird Song Transfers Information. PLoS One 3, e1580. https://doi.org/10.1371/journal.pone.0001580

Mendoza, I., Condit, R.S., Wright, S.J., Caubère, A., Châtelet, P., Hardy, I., Forget, P.-M., 2018. Inter-annual variability of fruit timing and quantity at Nouragues (French Guiana): insights from hierarchical Bayesian analyses. Biotropica 50, 431-441. https://doi.org/10.1111/btp.12560

Morrison, M.L., Marcot, B.G., Mannan, R.W.C.N.-Q.. M. 2006, 2006. Wildlife-habitat relationships: concepts and applications, 3rd ed. ed. Island Press, Washington.

Parks, S.E., Miksis-Olds, J.L., Denes, S.L., 2014. Assessing marine ecosystem acoustic diversity across ocean basins. Ecol. Inform. 21, 81-88. https://doi.org/10.1016/J.ECOINF.2013.11.003

Priyadarshani, N., Marsland, S., Castro, I., 2018. Automated birdsong recognition in complex 
acoustic environments: a review. J. Avian Biol. https://doi.org/10.1111/jav.01447

Ratiarison, S., Forget, P.-M., 2013. The Role of Frugivores in Determining Seed Removal and Dispersal in the Neotropical Nutmeg. Trop. Conserv. Sci. 6, 690-704. https://doi.org/10.1177/194008291300600508

Redford, K.H., 1992. The Empty Forest. Bioscience 42, 412-422. https://doi.org/10.2307/1311860

Richard-Hansen, C., Davy, D., Longin, G., Gaillard, L., Renoux, F., Grenand, P., Rinaldo, R., 2019. Hunting in French Guiana Across Time, Space and Livelihoods. Front. Ecol. Evol. 7, 289. https://doi.org/10.3389/fevo.2019.00289

Robin, X., Turck, N., Hainard, A., Tiberti, N., Lisacek, F., Sanchez, J.-C., Müller, M., 2011. pROC: an open-source package for R and S+ to analyze and compare ROC curves. BMC Bioinformatics 12, 77. https://doi.org/10.1186/1471-2105-12-77

Robinson, J.G., Redford, K.H., 1994. Measuring the sustainability of hunting in tropical forests. Oryx 28, 249. https://doi.org/10.1017/S0030605300028647

Rodriguez, A., Gasc, A., Pavoine, S., Grandcolas, P., Gaucher, P., Sueur, J., 2014. Temporal and spatial variability of animal sound within a neotropical forest. Ecol. Inform. 21, 133143. https://doi.org/10.1016/j.ecoinf.2013.12.006

Sharma, G., 2018. Acoustic Signal Classification for Deforestation Monitoring: Tree Cutting Problem. J. Comput. Sci. Syst. Biol. 11, 178-184. https://doi.org/10.4172/jcsb.1000269

Shonfield, J., Bayne, E.M., 2017. Autonomous recording units in avian ecological research: current use and future applications. Avian Conserv. Ecol. https://doi.org/10.5751/ace- 
00974-120114

Short, L.L., Horne, J.F.M., 2001. Toucans, barbets, and honeyguides: Ramphastidae, Capitonidae, and Indicatoridae, 1st ed. ed, Bird families of the world CN - QL696.P57 S56 2001. Oxford University Press, Oxford ; New York.

Slabbekoorn, H., Ripmeester, E.A.P., 2008. Birdsong and anthropogenic noise: implications and applications for conservation. Mol. Ecol. 17, 72-83. https://doi.org/10.1111/j.1365294X.2007.03487.x

Steel, E.A., Kennedy, M.C., Cunningham, P.G., Stanovick, J.S., 2013. Applied statistics in ecology: common pitfalls and simple solutions. Ecosphere 4, art115. https://doi.org/10.1890/ES13-00160.1

Steenweg, R., Hebblewhite, M., Kays, R., Ahumada, J., Fisher, J.T., Burton, C., Townsend, S.E., Carbone, C., Rowcliffe, J.M., Whittington, J., Brodie, J., Royle, J.A., Switalski, A., Clevenger, A.P., Heim, N., Rich, L.N., 2017. Scaling-up camera traps: monitoring the planet's biodiversity with networks of remote sensors. Front. Ecol. Environ. 15, 26-34. https://doi.org/10.1002/fee.1448

Stevens, H.C., Metz, E.M., Saboya Del Castillo, P., Alván, J.D., Bowler, M.T., 2019. Use of autonomous audio recordings for the rapid inventory of birds in the white-sand forests of the Peruvian Amazon. J. F. Ornithol. https://doi.org/10.1111/jofo.12279

Sueur, J., 2018. Sound Analysis and Synthesis with R, Use R! Springer International Publishing, Cham. https://doi.org/10.1007/978-3-319-77647-7

Sueur, J., Aubin, T., Simonis, C., 2008. Seewave, a free modular for sound analysis and 
synthesis. Bioacoustics 18, 213-226. https://doi.org/10.1080/09524622.2008.9753600

Sueur, J., Farina, A., 2015. Ecoacoustics: the Ecological Investigation and Interpretation of Environmental Sound. Biosemiotics 8, 493-502. https://doi.org/10.1007/s12304-0159248-x

Sugai, L.S.M., Silva, T.S.F., Ribeiro, J.W., Llusia, D., 2019. Terrestrial Passive Acoustic Monitoring: Review and Perspectives. Bioscience. https://doi.org/10.1093/biosci/biy147

Thiollay, J.-M., 2005. Effects of hunting on guianan forest game birds. Biodivers. Conserv. 14, 1121-1135. https://doi.org/10.1007/s10531-004-8412-4

Thomsen, P.F., Willerslev, E., 2015. Environmental DNA - An emerging tool in conservation for monitoring past and present biodiversity. Biol. Conserv. 183, 4-18. https://doi.org/10.1016/j.biocon.2014.11.019

Turner, W., 2014. Sensing biodiversity. Science (80-. ). 346, 301-302. https://doi.org/10.1126/science.1256014

Turner, W., Spector, S., Gardiner, N., Fladeland, M., Sterling, E., Steininger, M., 2003. Remote sensing for biodiversity science and conservation. Trends Ecol. Evol. 18, 306314. https://doi.org/10.1016/S0169-5347(03)00070-3

Ulloa, J.S., Gasc, A., Gaucher, P., Aubin, T., Réjou-Méchain, M., Sueur, J., 2016. Screening large audio datasets to determine the time and space distribution of Screaming Piha birds in a tropical forest. Ecol. Inform. 31, 91-99. https://doi.org/10.1016/j.ecoinf.2015.11.012

Van der Meer, P., Bongers, F., 1996. Patterns of tree-fall and branch-fall in a tropical rain forest in French Guiana. J. Ecol. 84, 19-29. https://doi.org/10.2307/2261696 
Wright, S.J., 2003. The myriad consequences of hunting for vertebrates and plants in tropical forests. Perspect. Plant Ecol. Evol. Syst. 6, 73-86. https://doi.org/10.1078/1433-831900043

Wunderle, J.M., 1997. The role of animal seed dispersal in accelerating native forest regeneration on degraded tropical lands. For. Ecol. Manage. 99, 223-235. https://doi.org/ 10.1016/S0378-1127(97)00208-9

Yack, T.M., Barlow, J., Calambokidis, J., Southall, B., Coates, S., 2013. Passive acoustic monitoring using a towed hydrophone array results in identification of a previously unknown beaked whale habitat. J. Acoust. Soc. Am. 134, 2589-2595. https://doi.org/10.1121/1.4816585

Yguel, B., Piponiot, C., Mirabel, A., Dourdain, A., Hérault, B., Gourlet-Fleury, S., Forget, P.M., Fontaine, C., 2019. Beyond species richness and biomass: Impact of selective logging and silvicultural treatments on the functional composition of a neotropical forest. For. Ecol. Manage. 433, 528-534. https://doi.org/10.1016/J.FORECO.2018.11.022

Young, H.S., McCauley, D.J., Galetti, M., Dirzo, R., 2016. Patterns, Causes, and Consequences of Anthropocene Defaunation. Annu. Rev. Ecol. Evol. Syst. 47, 333-358. https://doi.org/10.1146/annurev-ecolsys-112414-054142

Zuur, A.F., Ieno, E.N., Walker, N., Saveliev, A.A., Smith, G.M., 2009. Mixed effects models and extensions in ecology with R, Statistics for Biology and Health. Springer New York, New York, NY. 


\section{Figure legends}

Figure 1. Study area and recording sites. The study site is located in the southeast of French

Guiana in South America (left). The nine recording sites (A-I) were along the road RN2 connecting the cities of Cayenne and Saint-Georges-de-l'Oyapock. These sites were close to forest corridors ensuring a connectivity of the forest above the road. Picture by Michel Giraud-Audine.
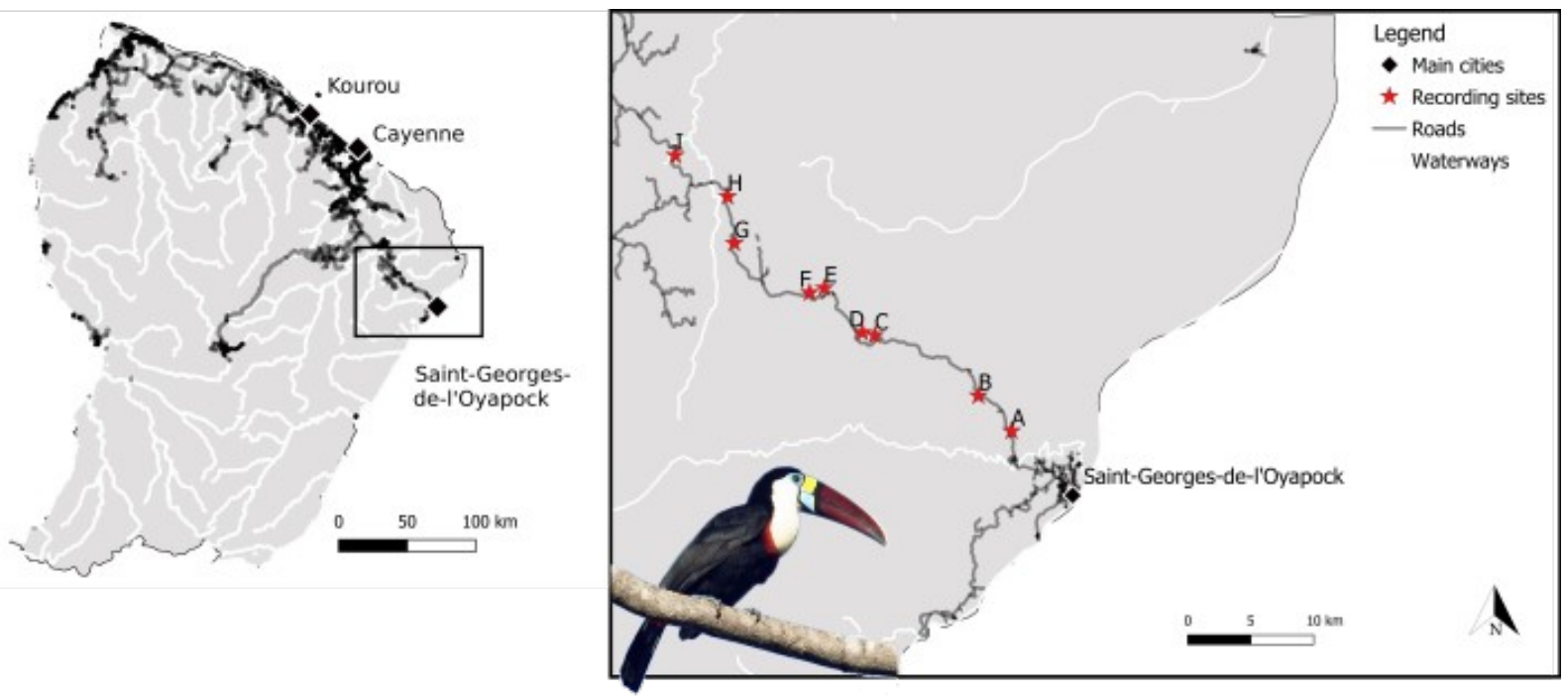
Figure 2. Spectrogram of a recording including Rhamphastos tucanus vocalizations. This section of a one-minute recording indicates $R$. tucanus vocalizations (red rectangles) within the complexity of the forest soundscape. Recording made at site D on 25 November 2017 at 07h20. Spectrogram specifications: Hamming window made of 512 samples with an overlap of $50 \%$, amplitude dynamic of $60 \mathrm{~dB}$. Full recording available as a sound voucher sample \#MNHN-SO-2019-91(https://sonotheque.mnhn.fr/sounds/MNHN/SO/2019-91).

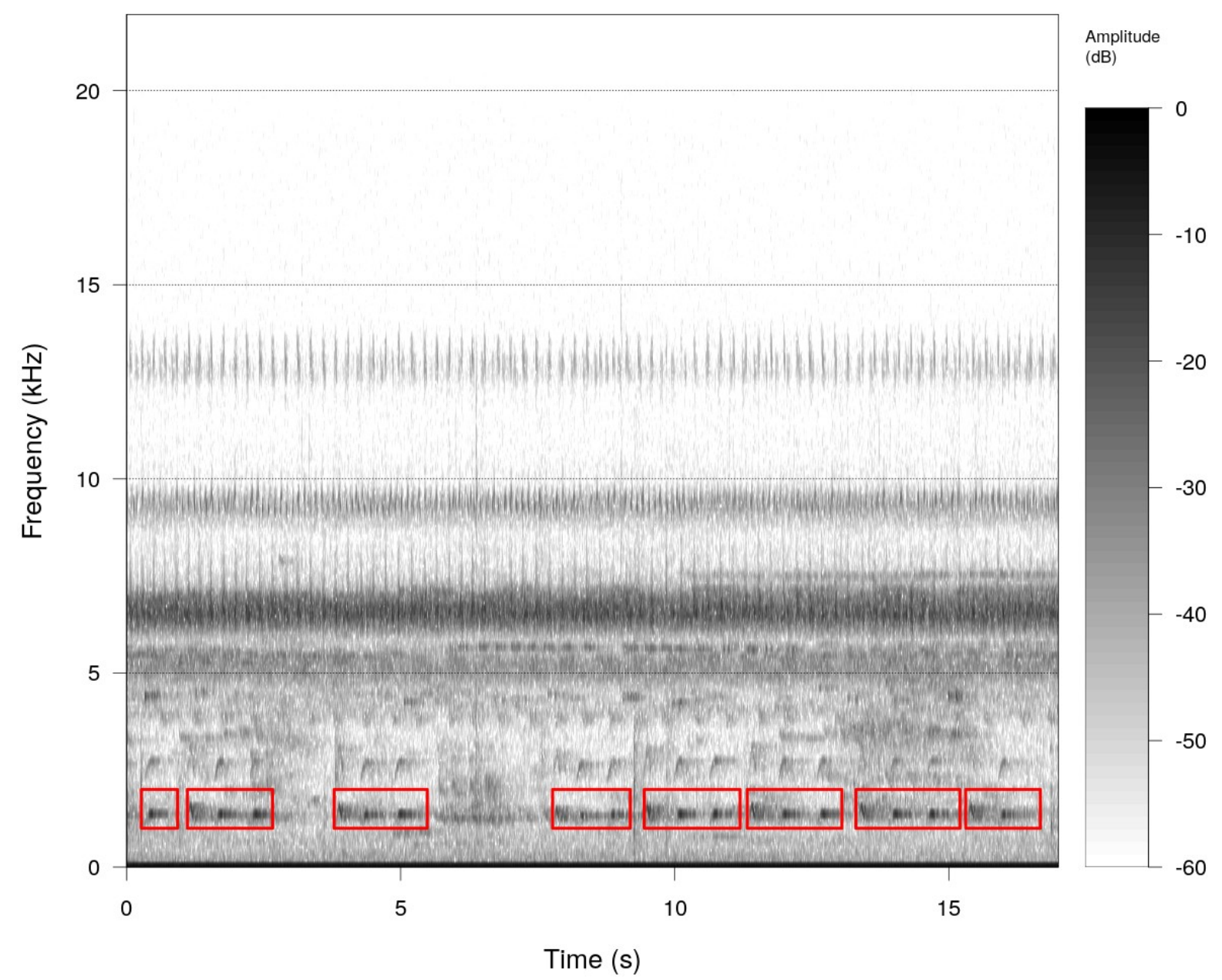


Figure 3. Time and space distribution of $R$. tucanus vocalizations detected. Heatmap

indicating the number of recordings with $R$. tucanus vocalizations detected automatically. The $x$-axis refers to time from early morning to night fall, sunrise and sunset occurring at 6:00 and 18:00 respectively. The $y$-axis corresponds to the nine recording sites (A-I). The grey scale ranges from 3 to 135. The margin barplots were obtained by summing up the columns (time distribution or phenology) and the rows of the heatmap matrix (space distribution).

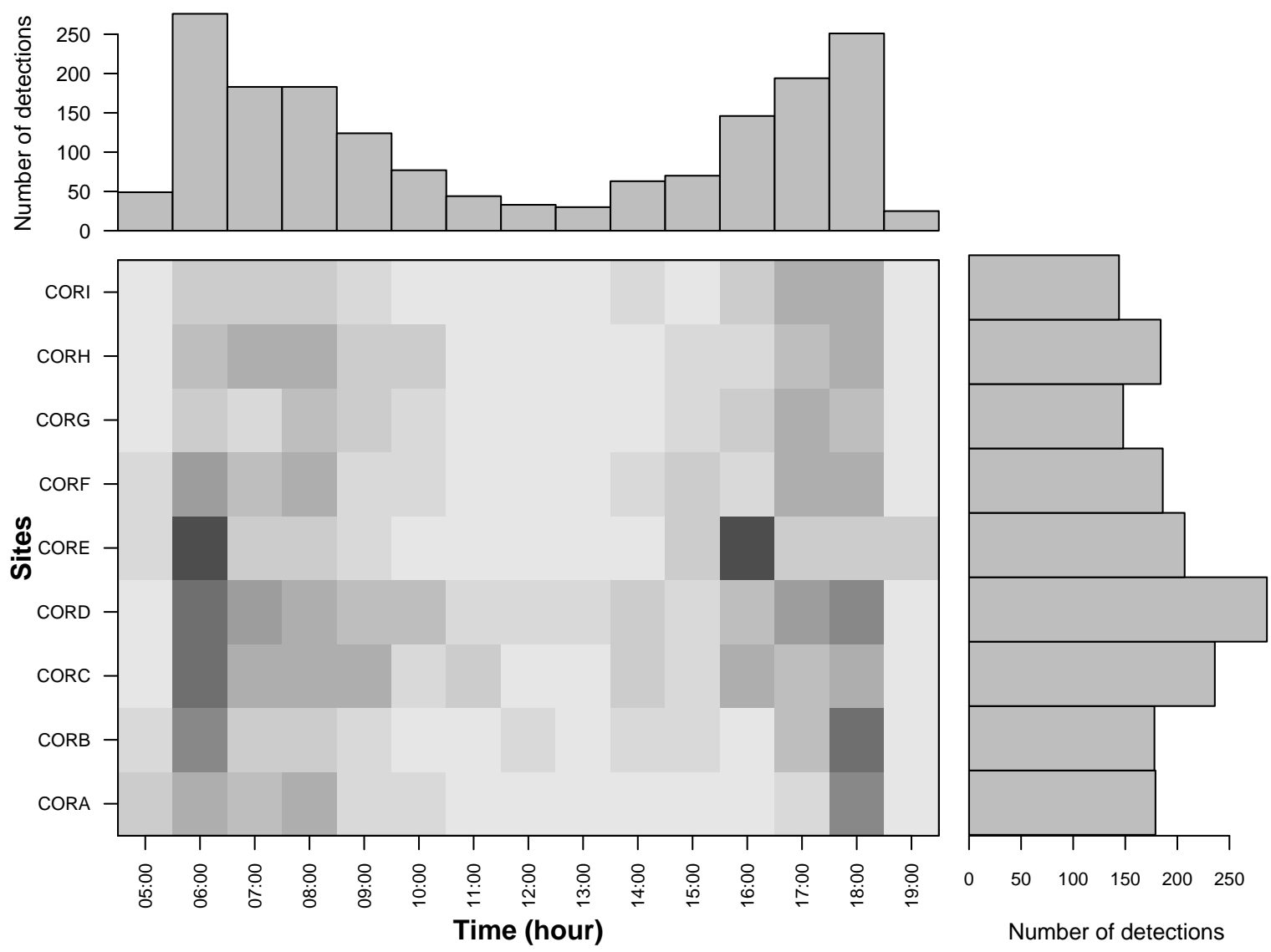


Figure 4. Plot of the model estimates using Incidence Rate Ratios. The $x$-axis refers to the Incidence Rate Ratios (IRR) values. The $y$-axis refers to the variable used in the model. The grey line is the limit for an IRR value of 1 meaning no effect. Contrast group for Habitat is 'Habitat 1'; contrast group for Human activity is "agricultural area”; contrast group for Hour is Hour5 (i.e. $5 \mathrm{am}) .\left({ }^{* *}\right)$ for p-values $<0.001,\left({ }^{* *}\right)$ for $\mathrm{p}$-values $<0.01$, $\left({ }^{*}\right)$ for p-values $<$ 0.05 .

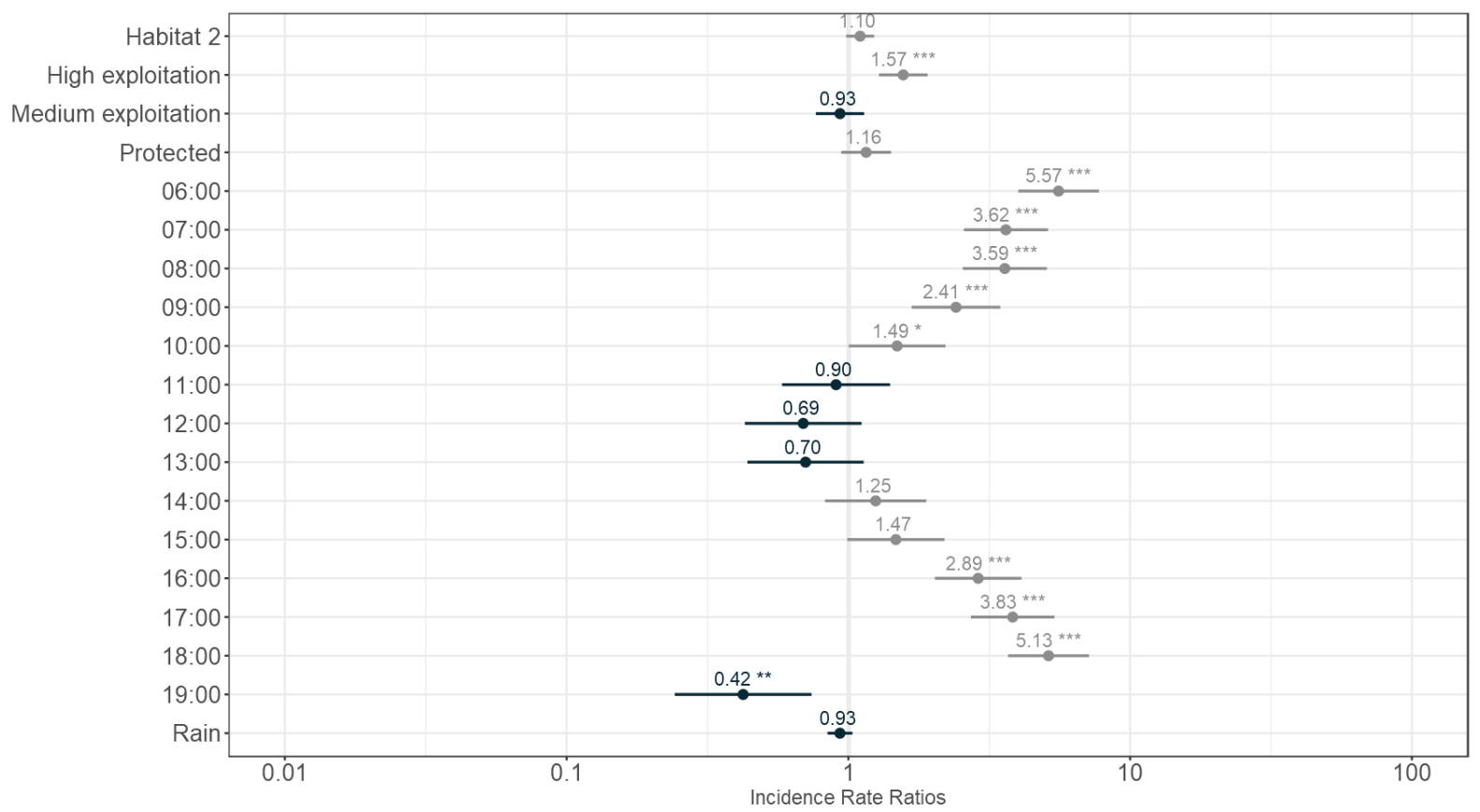


Figure 5. Comparison of the number of recordings with $R$. tucanus vocalizations detected and rainfall. The times series of the number of $R$. tucanus vocalization and the rainfall were compared using a dynamic time warping (DTW) process. The numbers indicate the time relation between the number of detections and the major rain events. The $x$-axis indicates the days of recording from 2017-11-26 to 2017-12-24. The left $y$-axis relates to the number of recordings with $R$. tucanus vocalizations detected. The right y-axis relates to the rainfall. The data were Z-transformed. The grey dotted lines connect the two times series indicating the compression and stretching operated by the DTW algorithm to find the best alignment. The numbers indicates the major events. The two-time series are shifted vertically for clarity.

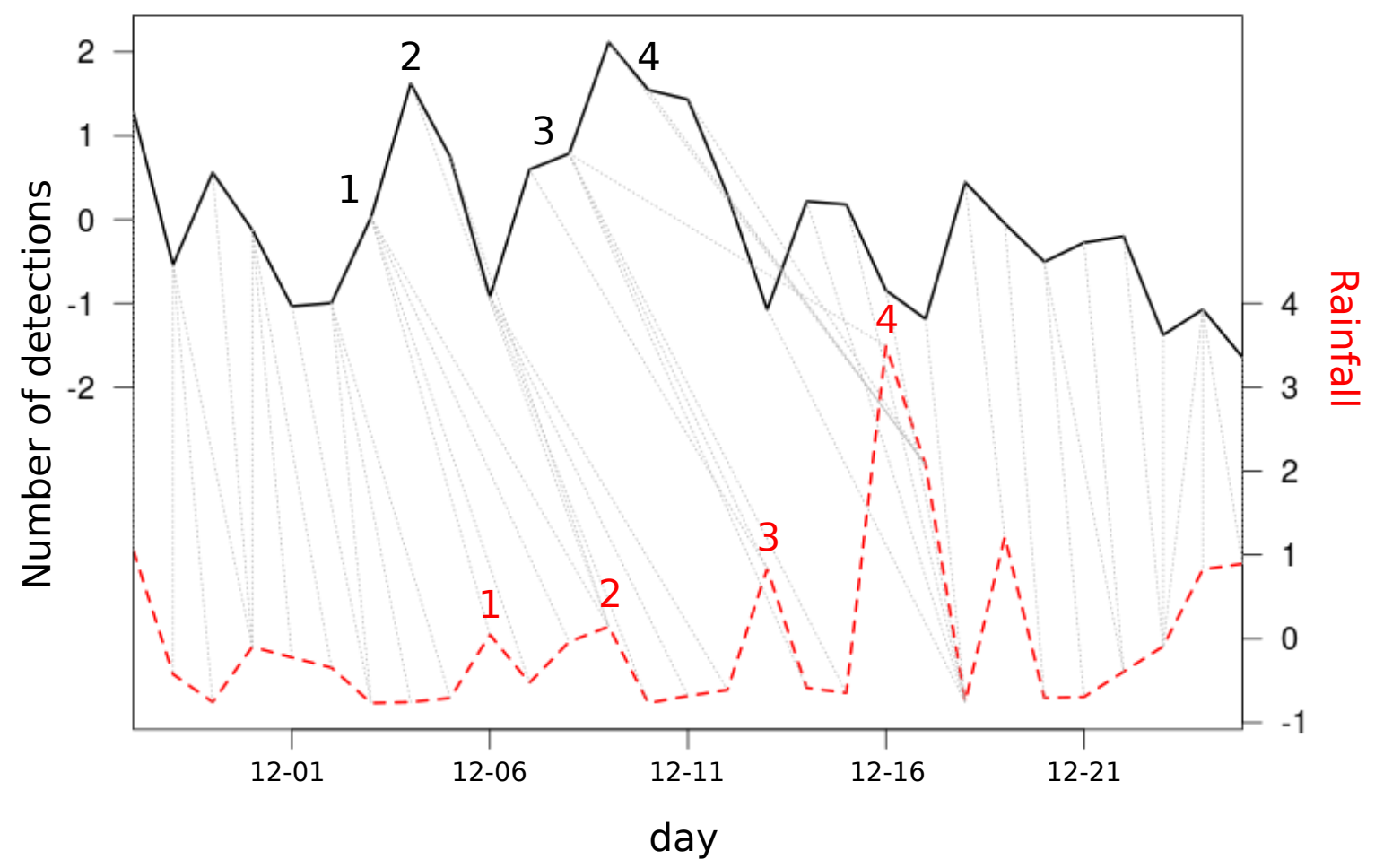




\section{Tables}

Table 1. Estimated coefficients from the Generalized Linear Mixed Model (GLMM) relating toucan vocal activity to habitat structure, human activity, rainfall and hour of the day.

Contrast group for Habitat is 'Habitat 1'; contrast group for HA (Human activity) is "agricultural area"; contrast group for Hour is Hour5 (i.e. $5 \mathrm{am}) .\left({ }^{* * *}\right)$ for P-values $<0.001$, $(* *)$ for P-values $<0.01,(*)$ for P-values $<0.05$.

\begin{tabular}{|c|c|c|c|c|}
\hline Predictor & Estimate & Std. error & $\mathrm{z}$ value & $P$-value \\
\hline (Intercept) & -1.89863 & 0.20886 & -9.090 & $<2 \mathrm{e}-16 * * *$ \\
\hline Habitat 2 & 0.04336 & 0.06582 & 0.659 & 0.510013 \\
\hline HA high exploitation & 0.42230 & 0.11748 & 3.595 & $0.000325 * * *$ \\
\hline HA medium exploitation & -0.04652 & 0.11313 & -0.411 & 0.680934 \\
\hline HA protected & 0.13421 & 0.12080 & 1.111 & 0.266583 \\
\hline Rainfall & -0.06845 & 0.05195 & -1.318 & 0.187633 \\
\hline Hour6 & 1.71756 & 0.16813 & 10.216 & $<2 \mathrm{e}-16 * * *$ \\
\hline Hour7 & 1.28803 & 0.17524 & 7.350 & $1.98 \mathrm{e}-13 * * *$ \\
\hline Hour8 & 1.27940 & 0.17545 & 7.292 & $3.05 \mathrm{e}-13^{* * *}$ \\
\hline Hour9 & 0.88047 & 0.18480 & 4.765 & $1.89 \mathrm{e}-06^{* * *}$ \\
\hline Hour10 & 0.39868 & 0.20190 & 1.975 & $0.048313^{*}$ \\
\hline Hour11 & -0.10066 & 0.22518 & -0.447 & 0.654855 \\
\hline Hour12 & -0.37074 & 0.24333 & -1.524 & 0.127613 \\
\hline
\end{tabular}




\begin{tabular}{lcccc}
\hline Hour13 & -0.35009 & 0.24242 & -1.444 & 0.148706 \\
\hline Hour14 & 0.22211 & 0.21101 & 1.053 & 0.292511 \\
\hline Hour15 & 0.38792 & 0.20263 & 1.914 & 0.059571. \\
\hline Hour16 & 1.06461 & 0.18029 & 5.905 & $3.52 \mathrm{e}-09^{* * *}$ \\
\hline Hour17 & 1.34389 & 0.17405 & 7.721 & $1.15 \mathrm{e}-14^{* * *}$ \\
\hline Hour18 & 1.63427 & 0.16884 & 9.679 & $<2 \mathrm{e}-16^{* * *}$ \\
\hline Hour19 & -0.85679 & 0.28497 & -3.007 & $0.002642^{* *}$ \\
\hline
\end{tabular}

